3. Change in acidity affects the shape of the absorption spectrum of diaminopimelic acid only. The absorption at $440 \mathrm{~m} \mu$ increases on decrease of $\mathrm{pH}$ from $\mathbf{1 \cdot 0}$ to $\mathbf{0 \cdot 3}$.

4. The reaction can be used for the estimation of diaminopimelic acid, provided that tryptophan, cystine, ornithine, proline and lysine are not present in excess.

\section{REFERENCES}

Chinard, F. P. (1952). J. biol. Chem. 199, 91.

Cocking, E. C. \& Yemm, E. W. (1954). Biochem. J. 58, xii.
Hoare, D. S. \& Work, E. (1955). Biochem. J. 61, 562.

Hoare, D. S. \& Work, E. (1957). Biochem. J. 65, 441.

Moore, S. \& Stein, W. H. (1954). J. biol. Chem. 211, 907.

Newton, G. G. F., Abraham, E. P. \& Berridge, N. J. (1953). Nature, Lond., 171, 606.

Piez, K. W., Irreverre, F. \& Wolff, H. L. (1956). J. biol. Chem. 223, 687.

Schweet, R. S. (1954). J. biol. Chem. 208, 603.

Work, E. (1957). Nature, Lond., 179, 841.

Work, E. \& Denman, R. F. (1953). Biochim. biophys. Acta, $10,183$.

Work, E. \& Dewey, D. L. (1953). J. gen. Microbiol. 9, 394.

\title{
Liver and Brain Mitochondria
}

\author{
By W. N. ALDRIDGE \\ Unit for Research in Toxicology, M.R.C. Laboratories, Carshalton, Surrey
}

(Received 1 May 1957)

Biochemical studies upon mitochondria may be undertaken from two points of view. The mechanism of the reactions mediated by the catalysts in the mitochondria may be the main interest, or studies may be made of biochemical properties of mitochondria in order to gain information to be applied to the physiology and biochemistry of the whole animal. Such points of view may overlap, but essentially the approach to the preparation and the environment in which the mitochondria are to be studied is different. For the study of mitochondria conditions may be used in which the reactions occur most efficiently; for correlation with studies of the whole animal the mitochondria should be undamaged and in a medium that resembles their normal intracellular environment. We are at present interested in the toxic action of 2:4-dinitrophenol and trialkyltin compounds, both of which act on the processes of oxidative phosphorylation in mitochondria (Loomis \& Lipmann, 1948; Aldridge \& Cremer, 1955). Such processes are particularly sensitive to modifications in the structure of mitochondria during their isolation and in their subsequent examination. If biochemical studies on these toxic agents are to be correlated with the physiology and pathology of the intoxicated animal, it seems essential to use mitochondria under natural conditions.

From a preliminary survey of the media which have been used for isolation and suspension, it was clear that they varied considerably in their tonicity and composition. Recent work (Opie, 1949; Opie \& Rothband, 1953; Robinson, 1950, 1952) has cast doubt on the accepted concept that the cells of the tissues are isotonic with blood (Peters, 1944). However, an isotonic solution to maintain the cell at its normal volume must contain substances which do not penetrate the cell (Davson, 1951). Since aqueous sodium chloride was used by these workers, and Leaf $(1955,1956)$ has shown that when tissues swell in Krebs-Ringer solutions sodium chloride passes into the cells, there is no evidence to support the concept that the contents of cells are hypertonic with respect to the extracellular fluid. Osmotic equality between intracellular and extracellular fluids agrees with the work of Deyrup (1953), who showed that slices of renal cortex do not swell in solutions of non-penetrating substances such as sucrose, maltose and lactose. The tonicity of the cytoplasm has been taken as $\mathbf{0 . 3}$ osmolar (Krebs \& Henseleit, 1932; Conway \& McCormack, 1953). In the intracellular fluid the cations present are potassium and magnesium and the bulk of the anions are phosphorus compounds (Hastings, 1940; Manery, 1954). The concentration of the main constituents of the intracellular fluid of the liver and brain (Table 1) have been calculated on the basis that chloride ions are extracellular (Truax, 1939; Hastings, 1940; Lowry, 1943 ; Manery, 1954) and the assumption that the other electrolytes are all in solution in the intracellular water. The results of these calculations for liver and brain are similar and a medium with a tonicity of 0.3 osmolar for mano metric experiments has been prepared with the proportions of potassium:magnesium:inorganic + nucleotide + phosphocreatine phosphorus, the same as those in the calculated composition of the intracellular fluid. 
The $\mathrm{pH}$ of the medium used for the study of mitochondria is almost always $\mathrm{pH} \mathbf{7 \cdot 4}$, although it is doubtful whether this is the $\mathrm{pH}$ of the intracellular fluid. Rous (1925) suggested that the intracellular fluid was more acid than the plasma and extracellular fluid. By the use of a micro-injection technique (Chambers \& Fell, 1931) it was concluded that the $\mathrm{pH}$ of the cytoplasm of a variety of cells is about 6.8 (Chambers, Pollack \& Hiller, 1927; Chambers \& Ludford, 1932; Chambers, 1940). Calculations from the bicarbonate concentration with the Henderson-Hasselbalch equation lead to values of about 6.9 (Hill \& Kupalov, 1930; Hastings, 1940) and a direct measure of the $\mathrm{pH}$ of the cytoplasm of crab muscle by means of micro-glass electrodes indicated $\mathrm{pH} \mathrm{6.9} \mathrm{(Caldwell,} \mathrm{1954).} \mathrm{It} \mathrm{is}$ thus uniformly agreed by workers who have considered the problem that the $\mathrm{pH}$ of intracellular fluid is below $\mathrm{pH}$ 7. The experiments described in this paper have been carried out at $\mathrm{pH} 6 \cdot 8$.

For a study of this kind it is essential to have a reliable measure of mitochondrial normality. The rate of oxidation of substances by mitochondria may be regulated by the availability of phosphate acceptors (Potter \& Rechnagel, 1951; Siekevitz \& Potter, 1953; Chance \& Williams, 1955). Some workers (Siekevitz \& Potter, 1953; Maley \& Lardy, 1955) have found that 2:4-dinitrophenol produces stimulation of the rate of oxidation by mitochondria ; others (Judah \& Williams-Ashman, 1951; Judah, 1951) have not found this. Organisms regulate energy production to their needs and part at least of this regulation may be mediated through the coupling of mitochondrial oxidation and phosphorylation. Also 2:4-dinitrophenol increases the metabolic rate of whole animals (Tainter \& Cutting, 1933; Stoner, 1956) and tissue slices (Fuhrman \& Field, 1942 $a, b$; Field, Tainter, Martin \& Belding, 1937; Terner, 1951 ; McIlwain, 1953). In this paper it is demonstrated that the rate of oxidation of a variety of substances by liver and brain mitochondria, isolated and studied as described below, is much increased by the addition of hexokinase and glucose, potato apyrase or 2:4-dinitrophenol. The power to react in this way is taken as a criterion of normality. Liver mitochondria show a high degree of stability at $37^{\circ}$ under these conditions, though brain mitochondria have not yet been obtained in as stable a condition.

This paper describes the methods whereby preparations of mitochondria showing these properties may be regularly obtained.

\section{METHODS}

\section{Purification of reagents}

All reagents were prepared in deionized water and stored in polythene bottles at $+5^{\circ}$.
Deionized water. Ordinary distilled water was passed through a mixed column of 1 part of Amberlite IR-120 (H) and 2 parts of IRA-400 (OH) (Davies \& Nancollas, 1950).

Potassium chloride. This was recrystallized from deionized water, and a stock solution ( $1.5 \mathrm{M})$ was prepared.

Magnesium chloride. The stock solution (finally $2 \mathrm{M}$ ) was shaken vigorously with $0.01 \%(w / v)$ dithizone in chloroform, the excess of dithizone removed by chloroform and the chloroform removed by aeration.

Potassium hydroxide. AnalaR KOH (British Drug Houses Ltd., $550 \mathrm{~g}$.) was dissolved in deionized water and diluted to $550 \mathrm{ml}$. After crystallizing at $+5^{\circ}$ overnight the crystals were drained at $+5^{\circ}$ and redissolved by heat in $50 \mathrm{ml}$. of water. Recrystallization took place at $+5^{\circ}$. After being drained the crystals were washed with $20 \mathrm{ml}$. of water, drained and dissolved in $300-400 \mathrm{ml}$. of deionized water to give a stock solution for neutralizing reagents.

Potassium phosphate. Phosphoric acid (0.15 M AnalaR; British Drug Houses Ltd.) was run down a column (3 ft. $\times$ $\frac{5}{8}$ in.) of Amberlite IR-120 (H). The acid was neutralized with purified $\mathrm{KOH}$, the phosphate concentration determined by analysis and the solution diluted to $0 \cdot 1 \mathrm{M}$.

Potassium $\beta$-glycerophosphate. Disodium $\beta$-glycerophosphate $(0.4 \mathrm{M})$ was run down a column ( $3 \mathrm{ft} . \times \frac{5}{8} \mathrm{in}$.) of Amberlite IR-120 (H) and the free acid neutralized with purified $\mathrm{KOH}$ and diluted to $0 \cdot 3 \mathrm{M}$.

Octanoic acid. This was redistilled twice in vacuo.

\section{Special chemicals and reagents}

The following chemicals were used unpurified and were obtained from the sources indicated: adenosine 5-phosphate (AMP), glycylglycine, L-glutamic acid, 2-oxoglutaric acid, sodium pyruvate, L-ascorbic acid, cocarboxylase (Roche Products Ltd.), disodium salt of adenosine triphosphate (ATP), coenzyme A, flavinadenine dinucleotide (FAD) (Sigma Chemical Co., St Louis, Mo., U.S.A.), ethylenediaminetetra-acetic acid (EDTA) (Hopkin and Williams Ltd.), glucose, disodium citrate, sodium fumarate (British Drug Houses Ltd.), L-malic, $\beta$-hydroxybutyric and lipoic acids (L. Light \& Co. Ltd.). All free acids were neutralized before use with purified $\mathrm{KOH}$.

Coenzyme I and cytochrome $c$ were prepared and assayed as previously described (Aldridge \& Cremer, 1955). Coenzyme II was prepared from ox liver by the method of Kornberg \& Horecker (1953). A yield of $1 \cdot 1 \mathrm{~g}$. was obtained by processing $1 \mathrm{cwt}$. of ox liver with purification on Dowex 1-X 2. Assayed by means of isocitric dehydrogenase, it contained $60 \%$ of coenzyme $\Pi$.

Potato apyrase was prepared by the method of Lee \& Eiler (1951). Assayed by the method of Krishnan (1949a) the preparation had an activity of $11000 \mathrm{units} / \mathrm{ml}$.

Hexokinase was prepared from baker's yeast by a modification by V. P. Parker (unpublished) of the method of Berger, Slein, Colowick \& Cori (1946). The preparation was taken to the equivalent of their step 5 and when assayed by their procedure (but at $37^{\circ}$ instead of $30^{\circ}$ ) this preparation had a specific activity of 1000 units and an activity of 4000 units $/ \mathrm{ml}$.

\section{Medium}

In Table 1 are shown the results of calculations of the composition of the intracellular fluid of rat liver and brain. These calculations are based on the assumption that the various ions are in solution in the intracellular fluid and are 
not bound appreciably by cytoplasmic particulates. From these results a medium has been devised with a similar ratio of potassium : magnesium : inorganic + nucleotide + phosphocreatine $P$. The medium given under 'Manometric techniques' has a molar ratio of 100:10:14. The osmolarity of this medium will be approx. $0 \cdot 31-0 \cdot 33$, the precise value depending on whether it is assumed that the magnesium salts of the phosphorus compounds are ionized. Chloride is the chief anion in this medium although intracellular fluid does not contain appreciable amounts and the main anions there are phosphate esters. As is shown below (Table 3), replacement of chloride by $\beta$-glycerophosphate does not alter the behaviour of the mitochondria.

\section{Preparation of mitochondria}

After the guillotining of the rats, the liver was quickly removed and rinsed with water; 7-8 g. was weighed and then disrupted in $30 \mathrm{ml}$. of ice-cold $0.3 \mathrm{M}$-sucrose with a PotterElvehjem-type homogenizer with a smooth glass tube and Perspex pestle (total clearance 0.030 in.). The pestle, revolving at $1500 \mathrm{rev} . / \mathrm{min}$., was taken 15 times up and down through the solution. Finally $45 \mathrm{ml}$. of ice-cold $0 \cdot 3$ M-sucrose was added. The nuclei and cellular debris were separated off by centrifuging at $850 \mathrm{~g}$ for $10 \mathrm{~min}$. at $0^{\circ}$. The mitochondria were then sedimented at $5000 \mathrm{~g}$ for $15 \mathrm{~min}$. After being washed once in $\mathbf{0 . 3} \mathrm{M}$-sucrose the mitochondria were suspended in $0.3 \mathrm{M}$-sucrose and the suspension was diluted to a volume (ml.) equal to twice the weight of the liver (g.).

For the isolation of brain mitochondria two rat brains (approx. 3.5 g.) were disrupted in $15 \mathrm{ml}$. of $0.3 \mathrm{M}$-sucrose with an homogenizer (total clearance 0.010 in.). The pestle, revolving at $1500 \mathrm{rev} . / \mathrm{min}$., was taken 15 times up and down through the solution. Finally, $25 \mathrm{ml}$. of ice-cold $0 \cdot 3 \mathrm{M}$-sucrose was added. It is essential to use an homogenizer with a smaller clearance than that used for liver. With an homogenizer with total clearance of 0.030 in., the finding of $70 \%$ of the succinic dehydrogenase in the nuclear and cellular debris indicated a large proportion of unbroken cells. Nuclear and cellular debris were removed at $1050 \mathrm{~g}$ for $10 \mathrm{~min}$. and mitochondria sedimented at $10000 \mathrm{~g}$ for $15 \mathrm{~min}$.

Table 1. Constituents of rat liver and brain

Distribution of water

\begin{tabular}{|c|c|c|}
\hline \multicolumn{3}{|c|}{ Distribution of water } \\
\hline & Liver & $\widehat{\text { Brain }}$ \\
\hline $\begin{array}{l}\text { Total water } \\
\text { Extracellular water (chloride space) } \\
\text { Intracellular water (diff.) }\end{array}$ & $\begin{array}{l}695(a) \\
217(c) \\
478\end{array}$ & $\begin{array}{l}786(b) \\
266(d) \\
520\end{array}$ \\
\hline
\end{tabular}

Concentration of anions and cations in intracellular water

\begin{tabular}{|c|c|c|c|c|}
\hline \multirow{3}{*}{$\begin{array}{l}\text { Cations } \\
\text { Potassi } \\
\text { Magnesi }\end{array}$} & \multicolumn{2}{|c|}{$\begin{array}{c}\text { Concn. in tissue } \\
\text { (m-mole/kg. wet wt.) }\end{array}$} & \multicolumn{2}{|c|}{$\begin{array}{l}\text { Concn. in intracellular water } \\
\text { (M) }\end{array}$} \\
\hline & Liver & Brain & Liver & Brain \\
\hline & $\begin{array}{rr}92 \cdot 2 & (e) \\
8.9 & (g)\end{array}$ & $\begin{array}{cc}100 & (f) \\
8 \cdot 1 & (g)\end{array}$ & $\begin{array}{l}0 \cdot 193 \\
0 \cdot 0186\end{array}$ & $\begin{array}{l}0 \cdot 193 \\
0 \cdot 0156\end{array}$ \\
\hline \multicolumn{5}{|l|}{ Anions } \\
\hline $\begin{array}{l}\text { Inorganic phosphate } \\
\text { AMP } \\
\text { ADP } \\
\text { ATP } \\
\text { Phosphocreatine } \\
\text { Acid soluble P }\end{array}$ & $\begin{array}{c}7.0 \quad(h) \\
0.94(h) \\
1.51(h) \\
1.38(h) \\
-\overline{6}(i)\end{array}$ & $\begin{array}{c}3 \cdot 7(h) \\
0 \cdot 12(h) \\
0 \cdot 72(h) \\
1 \cdot 65(h) \\
2 \cdot 60(h) \\
27 \cdot 1(j)\end{array}$ & $\begin{array}{l}0.0146 \\
0.0020 \\
0.0031 \\
0.0029 \\
-\overline{0}\end{array}$ & $\begin{array}{l}0.0071 \\
0.0002 \\
0.0014 \\
0.0032 \\
0.005 \\
0.052\end{array}$ \\
\hline
\end{tabular}

Molar proportions

\begin{tabular}{|c|c|c|}
\hline Molar proportions & & \\
\hline Potassium & Liver & Brain \\
\hline Magnesium & $\begin{array}{r}100 \\
10\end{array}$ & $\begin{array}{r}100 \\
8\end{array}$ \\
\hline norganic, nucleotide and creatine phosphorus & 16 & 13 \\
\hline
\end{tabular}

(a) Harrison (1953); Davidson \& Waymouth (1944); Dury \& Johnson (1951); Aebi (1955); Truax (1939); Laramore.\& Grollman (1950).

(b) Magee, Stoner \& Barnes (1957); Davenport (1950); Leiderman \& Katzman (1953); Manery \& Hastings (1939).

(c) Harrison (1953); Tobian, Morse \& Hastings (1955); Truax (1939).

(d) Manery \& Hastings (1939); Davenport (1950).

(e) Aebi (1955); Holland \& Auditore (1955); Truax (1939); Laramore \& Grollman (1950); Dury \& Johnson (1951); Rodeck \& Doden (1951).

(f) Manery \& Hastings (1939); Katzman \& Leiderman (1953); Leiderman \& Katzman (1953); Bergen \& Hoagland (1951); Magee et al. (1957); Davenport (1950).

(g) Watchorn \& McCance (1937).

(h) Threlfall, unpublished observations by the method of Threlfall (1957).

(i) Davidson, Frazer \& Hutchinson (1951); Stoner \& Threlfall (1954).

(j) Stoner \& Threlfall (1954). 


\section{Manometric technique}

Each flask contained $3 \mathrm{ml}$. of a solution containing AMP $(0.00115 \mathrm{M}), \operatorname{ATP}(0.00115 \mathrm{M}), \mathrm{KCl}(0.1 \mathrm{M}), \mathrm{MgCl}_{\mathbf{2}}(0.014 \mathrm{M})$, EDTA $(0.001 \mathrm{~m})$, potassium phosphate $(0.015 \mathrm{M})$, sucrose $(0.025 \mathrm{M})$ and substrates $(0.01 \mathrm{M}$; except fumarate, $0.001 \mathrm{M}$, and octanoate, $0.0017 \mathrm{~m}$ ). For studies of oxidative phosphorylation each flask contained in addition $180 \mu$ moles of glucose, $50 \mu$ moles of glycylglycine and $200-400$ units of hexokinase. In practice a stock solution of $\mathrm{KCl}, \mathrm{MgCl}_{2}$, EDTA and potassium phosphate was prepared at concentrations such that $2 \mathrm{ml}$. was required for each flask. The $\mathrm{pH}$ was adjusted to $\mathrm{pH} 6 \cdot 7-6.8$ and the solution stored at $+5^{\circ}$ in a polythene bottle. Before each experiment AMP, ATP and substrates and, for oxidative phosphorylation, glucose, glycylglycine and hexokinase were added and the $\mathrm{pH}$ was again adjusted to $\mathrm{pH}$ 6.7-6.8 with a glass electrode. All experiments were carried out at $37^{\circ}$. The oxidative activity of the mitochondria $\left(q_{\mathrm{O}_{2}}\right)$ is expressed as $\mu \mathrm{l}$. of $\mathrm{O}_{2} / \mathrm{mg}$. of protein $/ \mathrm{hr}$.

\section{Analytical methods}

Inorganic phosphate was determined by the method of Fiske \& Subbarow (1925).

Protein. The protein content of the mitochondrial suspension was determined by the following modification of the method of Robinson \& Hogden (1940). In our experience the solution obtained when the mitochondrial protein was precipitated with trichloroacetic acid was often opalescent. This may be readily prevented by deproteinizing with a mixture containing ( $v / v) 45 \%$ ethanol, $25 \%$ ether and $30 \%$ water. After centrifuging, the pellet of protein was dissolved in $1 \mathrm{ml}$. of $3 \%(\mathrm{w} / \mathrm{v}) \mathrm{NaOH}$, with warming if necessary, and $10 \mathrm{ml}$. of a fresh suspension of copper hydroxide was then added $\left[2.5 \mathrm{ml}\right.$. of $20 \%(\mathrm{w} / \mathrm{v}) \mathrm{CuSO}_{4}$, $5 \mathrm{H}_{2} \mathrm{O}$ was added quickly to $100 \mathrm{ml}$. of $3 \%(\mathrm{w} / \mathrm{v}) \mathrm{NaOH}$ and the suspension was shaken vigorously]. After standing for 10 min., with mixing 2-3 times, the solution was filtered twice through Whatman no. 54 filter paper and the optical density read at $555 \mathrm{~m} \mu$ against a blank run through the procedure. A calibration curve was prepared from dried bovine albumin (fraction V, Armour Laboratories) and the protein content of mitochondrial suspensions was expressed as mg. of albumin.

\section{RESULTS}

Liver mitochondria. Mitochondria prepared as described above oxidized substances of the Krebs tricarboxylic acid cycle very slowly (Table 2). However, by the addition of enzymes which remove ATP, such as hexokinase in the presence of glucose, or potato apyrase, or by the addition of 2:4-dinitrophenol, the rate of oxidation of these substances was increased three- to four-fold for pyruvate, $L$ glutamate, citrate, 2-oxoglutarate and twofold for octanoate and succinate. The degree of stimulation was consistent in different preparations.

The experiments in Table 3 show that replacement of chloride by $\beta$-glycerophosphate, a representative phosphate ester which is not appreciably oxidized, does not influence the rate of oxidation of pyruvate alone or in the presence of apyrase or 2:4-dinitrophenol.

Potter \& Rechnagel (1951) state that they failed to obtain stimulation of liver mitochondria by $2: 4$ dinitrophenol whereas Lardy succeeded, because they used potassium chloride in their medium at $38^{\circ}$ whereas Lardy (1951) used sucrose at $30^{\circ}$. The medium used for this work contains potassium chloride, and the results in Table 4 show that even washing liver mitochondria with isotonic potassium chloride does not affect the stimulation by apyrase or the phosphorylation quotient ( $\mathrm{P}: \mathrm{O}$ ratio) obtained for the oxidation of pyruvate.

Table 2. Stimulation by potato apyrase of oxidation of various substrates by liver and brain mitochondria

Each substrate was $0.01 \mathrm{M}$ except octanoate $(0.0017 \mathrm{M})$. Fumarate or succinate $(0.001 \mathrm{~m})$ was added to initiate oxidation of pyruvate or octanoate. Mitochondria were added to the medium with or without $0.1 \mathrm{ml}$. of apyrase (1100 units), the flasks equilibrated for $10 \mathrm{~min}$. and readings taken at $10 \mathrm{~min}$. intervals for a further $30 \mathrm{~min}$. These results are not corrected for any $\mathrm{O}_{2}$ uptake without substrate.

\begin{tabular}{|c|c|c|c|c|}
\hline \multirow[t]{2}{*}{ (1) } & \multicolumn{4}{|c|}{$q_{\mathrm{O}_{2}}$} \\
\hline & \multicolumn{2}{|c|}{ Liver } & \multicolumn{2}{|c|}{ Brain } \\
\hline Substrate & Normal & $\begin{array}{c}\text { With } \\
\text { apyrase }\end{array}$ & Normal & $\begin{array}{l}\text { With } \\
\text { apyrase }\end{array}$ \\
\hline Pyruvate/fumarate & 32 & 102 & 60 & 151 \\
\hline L-Glutamate & 26 & 96 & 46 & 100 \\
\hline Octanoate/fumarate & 57 & 104 & 21 & 16 \\
\hline Citrate & 33 & 102 & 17 & 17 \\
\hline Succinate & 55 & 102 & 72 & 98 \\
\hline 2-Oxoglutarate & 35 & 106 & 47 & 112 \\
\hline Fumarate & - & - & 37 & 26 \\
\hline Octanoate/succinate & - & - & 20 & 19 \\
\hline Glucose & - & - & 12 & 11 \\
\hline
\end{tabular}

Table 3. Effect of $\beta$-glycerophosphate upon normal and stimulated oxidation of pyruvate by liver mitochondria

Potassium chloride was replaced in the medium by an equi-osmolar amount of potassium $\beta$-glycerophosphate. This was calculated from a $\mathrm{pK}_{2}$ of 6.65 (Ashby, Crook \& Datta, 1954), assuming complete ionization of salts. Substrate was 0.01 Mpyruvate with $0.001 \mathrm{M}$-fumarate. Either $1.3 \times 10^{-5} \mathrm{M}$-2:4-dinitrophenol or $0.1 \mathrm{ml}$. of potato apyrase (1100 units) was used to stimulate oxidation.

\begin{tabular}{|c|c|c|c|}
\hline \multirow[b]{2}{*}{ Medium } & \multicolumn{3}{|c|}{$\underbrace{}_{\mathrm{O}_{2}}$} \\
\hline & Control & $\begin{array}{c}\text { With } \\
\text { 2:4-dinitrophenol }\end{array}$ & $\begin{array}{l}\text { With } \\
\text { apyrase }\end{array}$ \\
\hline $\begin{array}{l}\text { Potassium chloride } \\
\text { Potassium } \beta \text {-glycerophosphate }\end{array}$ & $\begin{array}{l}\mathbf{3 3} \\
\mathbf{3 8}\end{array}$ & $\begin{array}{r}98 \\
100\end{array}$ & $\begin{array}{l}102 \\
100\end{array}$ \\
\hline
\end{tabular}


The intracellular fluid of the liver cell contains approximately 0.015 M-glutathione (Lindan \& Work, 1953; Bhattacharya, Robson \& Stewart, 1955) which might protect the mitochondria from inactivation by heavy metal. At the outset it was considered that isolated mitochondria might be sensitive to trace metals in reagents. The reagents were therefore specially purified as described in Methods and 0.001M-EDTA was added to the medium. The results in Table 5 show that purification of commercially available reagents did not have a marked effect upon either the normal or the oxidation of pyruvate stimulated by apyrase. However, taking a probability of 0.05 as significant it is clear that the presence of EDTA did have a significant effect upon the stimulated oxidation either with purified or unpurified reagents. The addition of EDTA to the unpurified reagents increased both the resting $(P=0.04)$ and stimulated $(P=0.06)$ rates of oxidation, whereas the addition of EDTA to the purified reagents had little or no effect on the resting rate $(P=0.55)$ but some effect on the stimulated oxidation $(P=0 \cdot 06)$.

Although there is some evidence that the $\mathrm{pH}$ of intracellular fluids generally is below 7 , there is no direct evidence for rat liver. In Table 6 is shown the effect of variations of the $\mathrm{pH}$ of the medium upon the stimulation of pyruvate oxidation by apyrase. The amount of apyrase added in these experiments was three times that necessary to produce maximal stimulation. Since the $\mathrm{pH}$-activity curve for apyrase is very flat even at the extremes of $\mathrm{pH}$ there was sufficient apyrase activity to give maximal stimulation (Krishnan, 1949b). Between pH 6.65 and 7.16 there was a minimum normal resting rate coupled with a maximum stimulated rate. The $\mathrm{pH}$ used for experiments throughout this paper was around $\mathrm{pH}$ 6.8.

When hexokinase and glucose were used to trap ATP formed during the oxidation of pyruvate, a phosphorylation quotient of around $2 \cdot 70$ was obtained. The uptake of inorganic phosphate (Fig. 1) was linear until $90 \%$ had been esterified, and the rate of oxygen and phosphate uptake decreased at the same time. These experiments were carried out without the addition of fluoride and at $37^{\circ}$. For phosphorylation coupled to the oxidation of L-glutamate, phosphate uptake was not linear. Oxygen uptake was linear, but phosphate

Table 4. Effect of washing liver mitochondria with sucrose or potassium chloride solutions on oxidation of pyruvate and coupled phosphorylation

Mitochondria washed with 0.15M-potassium chloride were sedimented by $2500 \mathrm{~g} / 5 \mathrm{~min}$. and those washed with sucrose at $5000 \mathrm{~g}$ for $15 \mathrm{~min}$. Substrate was $0.01 \mathrm{~m}$ pyruvate with $0.001 \mathrm{M}$ fumarate. Apyrase (1100 units in $0 \cdot 1 \mathrm{ml}$.) was added. P:O ratios were determined as shown in Fig. 1.

\begin{tabular}{lccc} 
& \multicolumn{3}{c}{$q_{\mathrm{O}_{2}}$} \\
\cline { 2 - 4 } Normal & Apyrase & P:O \\
KCl washed & 24 & 97 & $2 \cdot 74$ \\
Sucrose washed & 24 & 99 & $2 \cdot 66$
\end{tabular}

\section{Table 5. Effect of purification of reagents on the oxidation of pyruvate by liver mitochondria}

Substrate was 0.01 M-pyruvate with 0.001 M-fumarate. Apyrase (0.1 ml.; 1100 units) was added. Uptake of $\mathrm{O}_{2}$ was calculated from the best straight line through readings taken at 20, 30, 40 and 50 min., after placing in the bath. Each value is the mean (with the standard error) of four experiments. The probability $(P)$ is derived from the standard $t$ test of each value against the corresponding value for purified reagents with EDTA.

\begin{tabular}{|c|c|c|c|c|}
\hline \multirow[b]{2}{*}{ Reagents } & \multicolumn{4}{|c|}{$q_{\mathrm{O}_{2}}$} \\
\hline & Normal & $P$ & With apyrase & $P$ \\
\hline $\begin{array}{l}\text { Purified + EDTA } \\
\text { Purified } \\
\text { Unpurified } \\
\text { Unpurified + EDTA }\end{array}$ & $\begin{array}{l}25 \cdot 7 \pm 0 \cdot 6 \\
24 \cdot 8 \pm 1 \cdot 3 \\
23 \cdot 9 \pm 1 \cdot 3 \\
28 \cdot 2 \pm 1 \cdot 0\end{array}$ & $\begin{array}{l}-\overline{0 \cdot 55} \\
0 \cdot 25 \\
0 \cdot 17\end{array}$ & $\begin{array}{l}96 \cdot 4 \pm 1 \cdot 8 \\
90 \cdot 0 \pm 2 \cdot 0 \\
84 \cdot 8 \pm 3 \cdot 4 \\
94 \cdot 5 \pm 2 \cdot 2\end{array}$ & $\begin{array}{l}-\overline{0.06} \\
0 \cdot 02 \\
0.55\end{array}$ \\
\hline
\end{tabular}

Table 6. Effect of $\mathrm{pH}$ on the oxidation of pyruvate by liver mitochondria

Substrate was 0.01 m-pyruvate and 0.001 m-fumarate. The pH of each solution was adjusted and read by means of a glass electrode. Apyrase (0.3 ml.; 3300 units) was used to stimulate the oxidation of the mitochondria.

\begin{tabular}{|c|c|c|c|}
\hline \multirow[b]{2}{*}{ pH } & \multicolumn{2}{|c|}{$q_{\mathrm{O}_{2}}$} & \multirow[b]{2}{*}{$\underset{(b / a)}{\text { Stimulation }}$} \\
\hline & $\underset{(a)}{\text { Normal }}$ & With apyrase & \\
\hline $\begin{array}{l}\mathbf{6 \cdot 1 0} \\
\mathbf{6 \cdot 3 6} \\
\mathbf{6 \cdot 6 5} \\
\mathbf{6 . 9 0} \\
\mathbf{7 \cdot 1 6} \\
\mathbf{7 \cdot 4 2}\end{array}$ & $\begin{array}{l}30 \\
26 \\
23 \\
25 \\
27 \\
34\end{array}$ & $\begin{array}{l}\mathbf{4 1} \\
\mathbf{5 9} \\
87 \\
\mathbf{9 3} \\
\mathbf{9 8} \\
\mathbf{9 0}\end{array}$ & $\begin{array}{l}\mathbf{1 . 4} \\
\mathbf{2 \cdot 3} \\
\mathbf{3} \cdot \mathbf{8} \\
\mathbf{3} \cdot \mathbf{7} \\
\mathbf{3 \cdot 6} \\
\mathbf{2 \cdot 6}\end{array}$ \\
\hline
\end{tabular}


uptake decreased, the phosphorylation quotient in the first $10 \mathrm{~min}$. being between 3.0 and 3.6 and decreasing steadily to $2 \cdot 5-2 \cdot 7$ over the period of 22 min., during which $75 \%$ of the phosphate was esterified. This phenomenon is not understood.

All the experiments previously described have been carried out without the addition of coenzymes or respiratory pigments. The addition of a variety

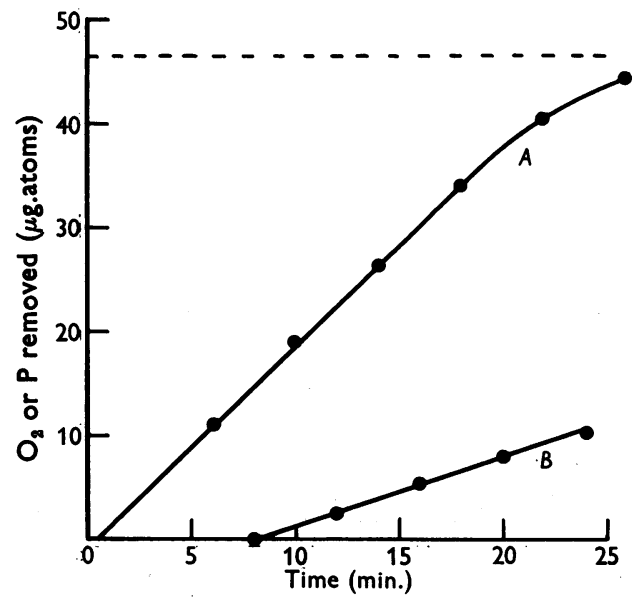

Fig. 1. Oxidative phosphorylation by liver mitochondria with pyruvate as substrate. Conditions of experiments are given in Methods. The interrupted line indicates the original amount of inorganic phosphate present. $A$, Uptake of phosphorus, $1.90 \mu \mathrm{g}$. atom/min.; $B$, uptake of oxygen, $0.69 \mu \mathrm{g}$. atom/min.; P:O ratio $2 \cdot 75$. of coenzymes had no effect upon the oxidation of pyruvate (Table 7). Liver mitochondria in the medium without the addition of coenzymes were stable. Oxidation of pyruvate stimulated fourfold by apyrase was almost linear for $2 \mathrm{hr}$. (Fig. 2). The resting rate of oxidation was linear for $3 \mathrm{hr}$. and if, at $2 \mathrm{hr}$., apyrase was added, oxidation was again

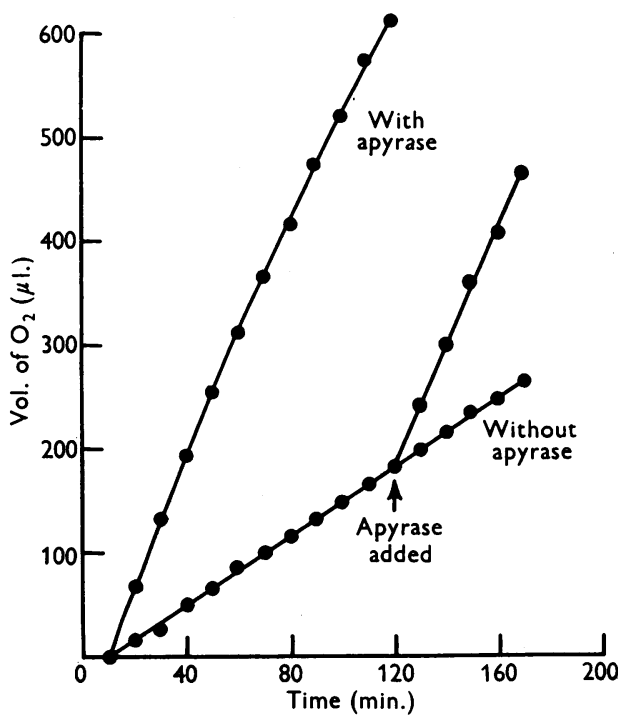

Fig. 2. Oxidation of pyruvate by liver mitochondria with and without apyrase. Apyrase (0.1 ml., 1100 units) was added. Mitochondria were added equivalent to $125 \mathrm{mg}$. of liver (protein $4.5 \mathrm{mg}$.).

Table 7. Effect of various cofactors on the normal and stimulated oxidation of pyruvate by liver and brain mitochondria

Substrate was 0.01 M-pyruvate with 0.001 M-fumarate. Potato apyrase was added to liver (1100 units) and to brain mitochondria (550 units) to stimulate the oxidation. Cofactor $(100 \mu \mathrm{g}$.) was added to each flask with the exception of cytochrome $c(490 \mu \mathrm{g}$.$) and glutathione (1 \mathrm{mg}$.$) .$

Expt.
no.

1

2

1

2
Cofactors added

Liver mitochondria

$\mathrm{Nil}$

Cytochrome $c$

Coenzymes I and II

Flavinadenine dinucleotide

Coenzyme $A$

All of above together

Nil

Cocarboxylase

L-Ascorbic acid

Glutathione

Brain mitochondria

Nil

Cytochrome c, Co I, Co II and FAD

Nil

Glutathione, ascorbic acid

Cocarboxylase, lipoic acid

Liver extract

$\overbrace{\substack{\text { Normal } \\(a)}}^{q_{\mathrm{O}_{2}}}{\underset{(b)}{\text { With apyrase }}}_{\substack{(b / a) \\ \text { Stimulation }}}$

$\begin{array}{rrr}25 & 96 & 3 \cdot 8 \\ 28 & \mathbf{9 7} & 3 \cdot 5 \\ 27 & 94 & 3 \cdot 5 \\ 24 & 89 & 3 \cdot 7 \\ 26 & 80 & 3 \cdot 1 \\ 24 & 88 & 3 \cdot 7 \\ 30 & 118 & \mathbf{3} \cdot 9 \\ 31 & 114 & 3 \cdot 7 \\ 27 & 115 & 4 \cdot 2 \\ 33 & 119 & 3 \cdot 6\end{array}$

$70 \quad 190$ 

Table 8. Phosphorylation quotients after partial inhibition by phenylarsenious acid
of the oxidation of pyruvate by liver mitochondria

Phenylarsine oxide was dissolved in $0.05 \mathrm{~N}-\mathrm{NaOH}$ to give a stock $3 \times 10^{-2} \mathrm{M}$-solution; solutions diluted with water were added to the flask before the addition of the mitochondria. P:O ratios were determined as shown in Fig. 1.

Concentration of phenylarsenious acid (M)

Nil

$1.2 \times 10^{-7}$ $2 \cdot 0 \times 10^{-7}$

$q_{\mathrm{o}_{2}}$
96
50
23

$q_{\mathrm{o}_{2}}$

50

23

$\mathrm{O}_{2}$ uptake
( $\mu$ g. atom/min.)
$0 \cdot 533$
$0 \cdot 280$
$0 \cdot 169$

$0 \cdot 169$
P uptake

( $\mu$ g. atom/min.)

$1 \cdot 28$

$0 \cdot 665$

$0 \cdot 420$
$\mathrm{P}: \mathrm{O}$

$2 \cdot 41$

$2 \cdot 38$

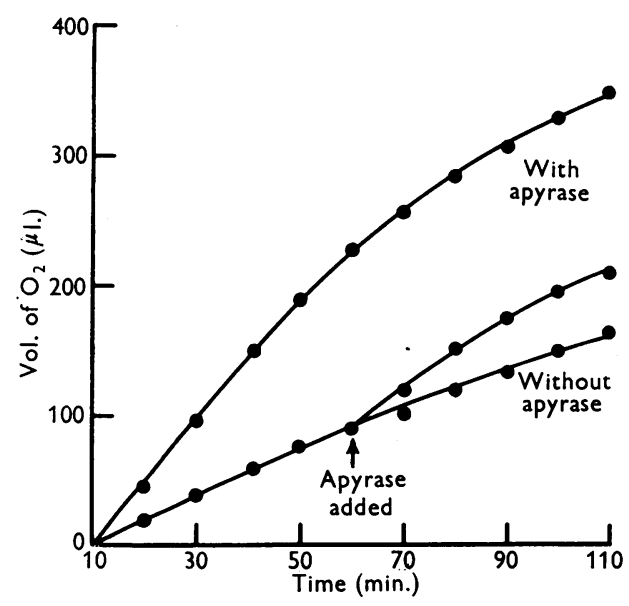

Fig. 3. Oxidation of pyruvate by brain mitochondria with or without apyrase. Apyrase (0.05 ml.; 550 units) was added. Mitochondria were added equivalent to $125 \mathrm{mg}$. of brain (protein $1.64 \mathrm{mg}$.).

stimulated fourfold. Further experiments show that it was possible to inhibit oxidation by $70-80 \%$ and still allow oxidative phosphorylation to proceed with unimpaired efficiency (Table 8). For this purpose phenylarsenious acid was used as a convenient respiratory inhibitor (Peters, 1955).

Brain mitochondria. Rat-brain mitochondria oxidized pyruvate, L-glutamate, 2-oxoglutarate and succinate rapidly, but citrate, fumarate and octanoate only slowly (Table 2). These findings are in agreement with the work of Brody \& Bain (1952) upon isolated mitochondria. Upon the addition of apyrase the oxidation of pyruvate, L-glutamate and 2-oxoglutarate was stimulated two- to three-fold (Table 2). A similar stimulation was obtained by the addition of hexokinase and glucose or 2:4dinitrophenol $\left(10^{-5} \mathrm{M}\right)$. These results are in contrast with those of Brody \& Bain (1952), who obtained little or no stimulation of the oxidation of pyruvate by the addition of hexokinase and glucose. Like liver mitochondria, brain mitochondria gave linear oxygen and phosphate uptake and phosphorylation quotients of about $2 \cdot 3$ were obtained.
However, these preparations of brain mitochondria were not as stable as liver mitochondria. The oxidation of pyruvate stimulated by apyrase was not linear and decreased rapidly after $1 \mathrm{hr}$. (Fig. 3). Addition of apyrase at $1 \mathrm{hr}$. did not raise the rate of oxidation to the original stimulated rate, but only approximately to the rate to which the stimulated preparation had fallen. Both resting and stimulated brain mitochondria were losing their ability to oxidize pyruvate. As shown in Table 7, the addition of a variety of coenzymes did not influence the resting or stimulated rates of oxidation. Further they had no influence upon the rate of loss of oxidizing ability.

\section{DISCUSSION}

In the medium described liver and brain mitochondria, isolated in $0.3 \mathrm{M}$-sucrose with the aid of a Potter-Elvehjem-type homogenizer, have low resting rates of oxidation of pyruvate and other substrates. Oxidation may be increased by systems utilizing ATP. Such an ability to respond to a stimulation is regarded as an essential property of mitochondria in vivo, although the normal extent of this stimulation is of course unknown. Both the method of isolation and the medium are important for the production of mitochondria which can be significantly stimulated in vitro at $37^{\circ}$. The homogenization technique utilizes the maximum clearance between pestle and tube consistent with obtaining a good yield of mitochondria. An uptake of $3000 \mu \mathrm{l}$. of $\mathrm{O}_{2} / \mathrm{hr}$./g. may be regularly obtained with liver if a clearance of $0.020-0.030 \mathrm{in}$. is used, whereas to obtain this result with brain a clearance of $0.010 \mathrm{in}$. or less must be used. Purity of reagents does not appear to be an important factor influencing the behaviour of liver mitochondria. Under the conditions described, liver mitochondria are stable, may bestimulated three- to four-fold by the addition of apyrase and give high $P: O$ ratios without the addition of coenzymes or fluoride. Inhibition of oxidation by $70-80 \%$ allows oxidative phosphorylation to proceed with unimpaired efficiency.

Although the preparations of brain mitochondria are considerably more stable than others previously 
described (Brody \& Bain, 1952; Christie, Judah \& Rees, 1953) they are not as stable as liver mitochondria. The decrease of their oxidative potentialities after $50-60 \mathrm{~min}$. is not prevented by the addition of coenzyme I, coenzyme II, cytochrome C, flavinadenine dinucleotide, lipoic acid, cocarboxylase, glutathione or ascorbic acid.

Some workers state that brain mitochondria, unlike liver preparations, contain the glycolytic system (Gallagher, Judah \& Rees, 1956; DuBuy \& Hesselbach, 1956), whereas the contrary has been concluded from other experimental results (Brody \& Bain, 1952; Abood, Gerard, Banks \& Tschirgi, 1952). In this work brain mitochondria oxidize glucose at less than $10 \%$ of the rate of oxidation of pyruvate. Crane \& Sols (1953) claim that a large proportion of the hexokinase of rat brain is sedimented at speeds used to separate mitochondria. If the amounts of hexokinase described by Crane \& Sols (1953) had been present in our mitochondria, appreciable esterification of inorganic phosphate should take place on the addition of glucose to mitochondria oxidizing pyruvate. In fact preliminary experiments have shown that the addition of glucose slightly stimulates oxidation (1.3 times), and esterification of inorganic phosphate equivalent to a phosphorylation quotient of $\mathbf{0 . 3}$ is found. There are therefore several discrepancies in the published information on brain mitochondria. Brain is a difficult organ from which to obtain 'pure' preparations of mitochondria. Preliminary experiments with phase contrast and interference microscopy show that the preparation used in this work was not homogeneous. Until more homogeneous preparations are obtained it is not possible to conclude that brain mitochondria contain the glycolytic system.

Suitably prepared liver mitochondria are both stable and versatile in vitro. They appear to be autonomous with regard to supplies of coenzymes and respiratory pigments. The fact that they can retain such substances may account for their stability in vitro. Brain mitochondria are not so stable though they appear to be self-sufficient in supplies of a variety of cofactors. It is not possible to say yet with certainty whether they differ significantly in their metabolic activities from liver mitochondria, for example in possessing the glycolytic mechanism. It is certain that the preparations from brain were not so free from other cellular fractions as the liver mitochondria. Either of these differences might explain their instability, but if the latter is the explanation it should be possible to achieve stable preparations eventually.

\section{SUMMARY}

1. A medium based upon the composition of the intracellular fluid of liver and brain has been devised for use in the study of mitochondria.
2. The rate of oxidation of various substrates is low, but may be increased three- to four-fold for liver and two- to three-fold for brain mitochondria by the addition of hexokinase and glucose, potato apyrase or 2:4-dinitrophenol.

3. In the study of oxidative phosphorylation with hexokinase and glucose as trapping agents, the esterification of inorganic phosphate is linear at $37^{\circ}$ until more than $90 \%$ has been removed.

4. Liver mitochondria are stable during oxidation of pyruvate for at least $3 \mathrm{hr}$.

5. The rate of oxidation of pyruvate by brain mitochondria decreases after 50-60 min. The addition of a variety of coenzymes does not.influence this loss of activity.

I am indebted to Mr B. W. Street for his skilled and painstaking technical assistance and to Dr A. H. Ford-Moore for the phenylarsine oxide.

\section{REFERENCES}

Abood, L. G., Gerard, R. W., Banks, J. \& Tschirgi, R. D. (1952). Amer. J. Physiol. 168, 728.

Aebi, H. (1955). Helv. physiol. acta, 11, 96.

Aldridge, W. N. \& Cremer, J. E. (1955). Biochem. J. 61, 406.

Ashby, J. H., Crook, E. M. \& Datta, S. P. (1954). Biochem.J. 56, 198.

Bergen, J. R. \& Hoagland, H. (1951). Amer. J. Physiol. 164, 23.

Berger, L., Slein, M. W., Colowick, S. P. \& Cori, C. F. (1946). J. gen. Physiol. 29, 379.

Bhattacharya, S. K., Robson, J. S. \& Stewart, C. P. (1955). Biochem. J. 60, 696.

Brody, T. M. \& Bain, J. A. (1952). J. biol. Chem. 195, 685. Caldwell, P. C. (1954). J. Physiol. 126, 169.

Chambers, R. (1940). Cell and Protoplasm, Publ. Amer. Ass. Advanc. Sci. no. 14, p. 20.

Chambers, R. \& Fell, H. B. (1931). Proc. Roy. Soc. B, 109, 380.

Chambers, R. \& Ludford, R. J. (1932). Proc. Roy. Soc. B, $110,120$.

Chambers, R., Pollack, H. \& Hiller, S. (1927). Proc. Soc. exp. Biol., N.Y., 24, 760.

Chance, B. \& Williams, G. R. (1955). Nature, Lond. 175, 1120.

Christie, G. S., Judah, J. D. \& Rees, K. R. (1953). Proc. Roy. Soc. B, 141, 523.

Conway, E. J. \& McCormack, J. I. (1953). J. Physiol. $120,1$.

Crane, R. K. \& Sols, A. (1953). J. biol. Chem. $203,273$.

Davenport, V. D. (1950). Amer. J. Physiol. 163, 633.

Davidson, J. N., Frazer, S. C. \& Hutchinson, W. C. (1951). Biochem. J. 49, 311.

Davidson, J. N. \& Waymouth, C. (1944). Biochem. J. 38, 379.

Davies, C. W. \& Nancollas, G. H. (1950). Chem. \& Ind. p. 129.

Davson, H. (1951). A Textbook of General Physiology. London: Churchill Ltd.

Deyrup, I. (1953). J. gen. Physiol. 36, 739.

DuBuy, H. G. \& Hesselbach, M. L. (1956). J. Histochem. Cytochem. 4, 363. 
Dury, A. \& Johnson, T. N. (1951). Proc. Soc. exp. Biol., N.Y., 78, 425.

Field, J., Tainter, E. G., Martin, A. W. \& Belding, H. S. (1937). Amer. J. Ophthal. 20, 779.

Fiske, C. H. \& Subbarow, Y. (1925). J. biol. Chem. 66, 375.

Fuhrman, F. A. \& Field, J. (1942a). Proc. Soc. exp. Biol., N.Y., 49, 504.

Fuhrman, F. A. \& Field, J. (1942b). J. Pharmacol. 75, 58.

Gallagher, C. H., Judah, J. D. \& Rees, K. R. (1956). Biochem. J. $62,436$.

Harrison, M. F. (1953). Proc. Roy. Soc. B, 141, 203.

Hastings, A. B. (1940). Harvey Lect. 36, 91.

Hill, A. V. \& Kupalov, P. S. (1930). Proc. Roy. Soc. B, 106, 445.

Holland, W. C. \& Auditore, G. V. (1955). Amer. J. Physiol. 183, 309.

Judah, J. D. (1951). Biochem. J. 49, 271.

Judah, J. D. \& Williams-Ashman, H. G. (1951). Biochem. J. 48, 33.

Katzman, R. \& Leiderman, P. H. (1953). Amer. J. Physiol. 175, 263.

Kornberg, A. \& Horecker, B. L. (1953). Biochem. Prep. 3, 24.

Krebs, H. A. \& Henseleit, K. (1932). Hoppe-Seyl. Z. 210, 33.

Krishnan, P. S. (1949a). Arch. Biochem. 20, 261.

Krishnan, P. S. (1949b). Arch. Biochem. 20, 272.

Laramore, D. C. \& Grollman, A. (1950). Amer. J. Physiol. 161, 278.

Lardy, H. A. (1951). A Symposium on Phosphorus Metabolism. Lansing: Michigan State College Press.

Leaf, A. (1955). Biochem. J. 60, xl.

Leaf, A. (1956). Biochem. J. 62, 241.

Lee, K. H. \& Eiler, J. J. (1951). Science, 114, 393.

Leiderman, P. H. \& Katzman, R. (1953). Amer. J. Physiol. 175, 271.

Lindan, O. \& Work, E. (1953). Biochem. J. 55, 554.
Loomis, W. F. \& Lipmann, F. (1948). J. biol. Chem. 173, 807.

Lowry, O. H. (1943). Biol. Symp. 10, 233.

McIlwain, H. (1953). Biochem. J. 53, 403.

Magee, P. N., Stoner, H. B. \& Barnes, J. M. (1957). J. Path. Bact. 73, 107.

Maley, G. F. \& Lardy, H. A. (1955). J. biol. Chem. 215, 377.

Manery, J. F. (1954). Physiol. Rev. 84, 334.

Manery, J. F. \& Hastings, A. B. (1939). J. biol. Chem. 127, 657.

Opie, E. L. (1949). J. exp. Med. 89, 185.

Opie, E. L. \& Rothband, M. B. (1953). J. exp. Med. 97, 483.

Peters, J. P. (1944). Physiol. Rev. 24, 491.

Peters, R. A. (1955). Johns Hopk. Hosp. Bull. 97, 1.

Potter, V. R. \& Rechnagel, R. O. (1951). Phosphorus Metabolism, vol. 1, p. 377. Baltimore: Johns Hopkins Press.

Robinson, H. W. \& Hogden, C. G. (1940). J. biol. Chem. 135, 709.

Robinson, J. R. (1950). Proc. Roy. Soc. B, 137, 378.

Robinson, J. R. (1952). Proc. Roy. Soc. B, 140, 135.

Rodeck, H. \& Doden, W. (1951). Z. ges. exp. Med. 117, 414.

Rous, P. (1925). J. exp. Med. 41, 739.

Siekevitz, P. \& Potter, V. R. (1953). J. biol. Chem. 201, 1.

Stoner, H. B. (1956). Brit. J. exp. Path. 37, 176.

Stoner, H. B. \& Threlfall, C. J. (1954). Biochem. J. 58, 115.

Tainter, M. L. \& Cutting, W. C. (1933). J. Pharmacol. 48, 410.

Terner, C. (1951). Biochem. J. 50, 145.

Threlfall, C. J. (1957). Biochem. J. 65, 694.

Tobian, L., Morse, W. I. \& Hastings, A. B. (1955). Proc. Soc. exp. Biol., N.Y., 90, 97.

Truax, F. L. (1939). Amer. J. Physiol. 126, 402.

Watchorn, E. \& McCance, R. A. (1937). Biochem. J. 31, 1379.

\title{
An Electronic Colloid Osmometer and an Assessment of its Accuracy. The Molecular Weight of Bovine Plasma Albumin
}

\author{
By D. S. ROWE AND M. E. ABRAMS \\ Department of Experimental Pathology, University of Birmingham
}

(Received 18 February 1957)

This osmometer was designed to study the changes occurring in serum and allied proteins in disease. An instrument was required to measure colloid osmotic pressure accurately and rapidly on small volumes of solution. Although the osmometers of Adair (e.g. Adair, 1925) were accurate they took $24 \mathrm{hr}$. or more to come to equilibrium, and required several millilitres of solution. The osmometer of Smithies (1953) yielded results of high accuracy on small volumes of solution, but also took many hours to reach equilibrium. A form of electronic osmometer has already been described briefly (Rowe, 1953), and in this paper an assessment of the developed form of the instrument is presented. The results obtained with bovine plasma albumin showed that measurements of high accuracy could be obtained in $30 \mathrm{~min}$. on small volumes of solution.

\section{EXPERIMENTAL}

Principle. The osmometer is in the form of a U-tube, with the semi-permeable membrane inserted into one limb (Fig. 1). The membrane separates protein solution from solvent, and the flow of solvent through the membrane due to colloid osmotic pressure is opposed by an air pressure applied to the solution. When the tap is closed any flow through the membrane produces a rapid pressure change in the compartment between the membrane and the tap. This causes movements of a platinum foil in the wall of this 